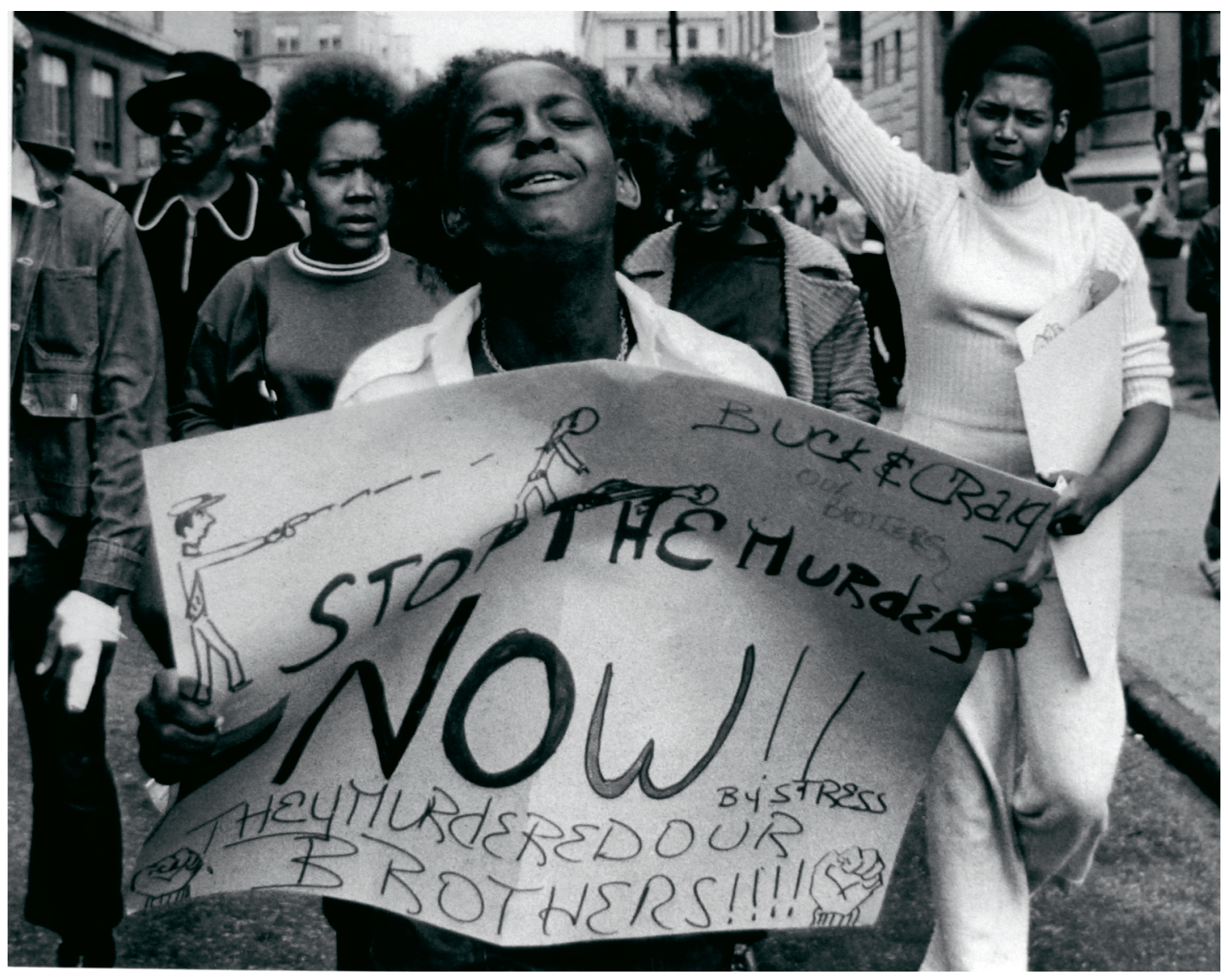


n. 28 Rito e violência - vigília pelos 111, por Nuno Ramos

\section{Ritual and violence - vigil by the 111 , by Nuno Ramos}

palavras-chave: 111; massacre do Carandiru; Nuno Ramos

keywords: 111; Carandiru massacre; Nuno Ramos

* Universidade Federal de Brasília [UnB].

Ken Hamblin, Detroit Police Headquarters, Beaubien Street
Este artigo visa analisar as propostas de Nuno Ramos 111 (1992), O dia deles - 24 horas 111 (2012) e 111, a vigília (2016), todas versando sobre o grande massacre levado a cabo pela polícia dentro da Casa de detenção Carandiru, em 1992. A análise procura pensar, de forma um tanto aberta, como o Estado de Direito brasileiro é flagrado em seus antagonismos por essas imagens e instalações.

This article aims to analyze the works of Nuno Ramos 111 (1992), Their day24 hours 111 (2012) e 111, a vigil (2016). The works show the great massacre carried out by the police inside the Carandiru detention house in 1992. The analysis of the images and artworks aims to show the antagonisms of the Brazilian State of Law. 
Prometeu desafia o destino com digna coragem, luta contra ele, com ou sem sorte, e não é deixado pela lenda sem a esperança de trazer um dia um novo direito. É, no fundo, esse herói e a violência de direito do mito que lhe é intrínseca que o povo tenta presentificar, ainda nos dias de hoje, quando admira o grande criminoso. ${ }^{1}$

Eu quis ver mas não o vi. Eu quis ter mas não o tive. Eu quis. Eu quis o deus mas não o tive. Eu quis o homem, o filho, o primeiro bicho mas não os pude ver. Estava deitado, desperto. Estava desde o início. Quis me mover mas não me movi. Eu quis. Estava debruçado, morto desde o início. A grama alta quase não me deixava ver. Estava morto desde o comecinho. Eu quis o medo mas não o pude ter. Estava deitado, debruçado bem morto. Quis ver o primeiro bicho e a raiz da primeira planta. ${ }^{2}$

Na primeira cena da tragédia que leva seu nome, Édipo, na carne do tirano que tirou Tebas das garras da esfinge, busca agora purgar a cidade dos miasmas malignos que as erínias infringem à população pela morte do rei Laio. Aquietar as erínias, as fúrias do sangue que comandam a ordem violenta do genos, dos laços primitivos de parentesco, funciona na tragédia também como ação de aquietar o cosmos da pólis, em uma nova ordem, que se constitui como o outro da família e do genos; se constitui como o espaço público do Direito. Espaço fundado, todavia, e a tragédia se mantém a um passo desse abismo, sobre o informe violento originário, cujos laços de sangue, naturais, quentes, ainda vibram na vingança necessária.

Como nos ensina Jean-Pierre Vernant, é nesse espaço de intersecção entre o abismo sanguíneo da violência, da vingança que move outras ordens de vinganças, e uma arena acordada sob normas universais, a pólis, que se equilibra uma nova noção normativa do Direito. A Dike contém a eunomia, e o assassinato deixa a esfera do privado, do sangue, do genos, e passa à norma, ao nomos, à pólis. Escreve Vernant:

\section{Priscila R. Rufinoni}

Rito e violência - vigília pelos

111, por Nuno Ramos

1. BENJAMIN, Walter. Para uma crítica da violência. In: Escritos sobre mito e linguagem. São Paulo: Duas cidades/Editora 34, 2011, p. 147.

2. RAMOS, Nuno, trecho de "Cujo", parte da instalação 111, 1992. 
3. VERNANT, Jean-Pierre.

As origens do pensamento grego. Rio de Janeiro: Bertrand Brasil, 1996, p. 5.

4. LORAUX, Nicole. Elogio do anacronismo em história. In: A tragédia de Atenas - A política entre as trevas e a utopia. São Paulo: Loyola, 2009.

5. De forma aproximada, Walter Benjamin, em um texto que norteia este ensaio, toma a manifestação pura da violência divina nos mitos, distante tanto do Direito natural quanto da justiça dos meios e dos fins, como possibilidade de pensar a origem de todo Direito, seja qual for o uso administrado do poder violento. Trata-se do ensaio de 1921, cujo título, na tradução de Ernani Chaves, é “Por uma crítica da violência", e, na de Willi Bolle, "Crítica da violência - crítica do poder", atentando à especificidade do vocábulo alemão Gewalt, que carrega a ambiguidade violência e/ou poder. Ver nota de Chaves à tradução citada, em BENJAMIN, Walter. Op. cit., 2011, p. 121-122. por toda espécie de assassínio, a observação do miasma que pode representar para uma cidade o sangue derramado, a exigência de uma expiação que é ao mesmo tempo uma purificação do mal - todas essas atitudes estão ligadas ao despertar religioso que se manifesta no dionisismo e que se reveste, em meios mais especializados, a forma de um movimento de seitas como os "Órficos". 3

Mais que religiosas, essas pragas são conselheiras políticas dos nomótetas e se associam à obra dos legisladores míticos de primeiro momento. Claro que Vernant, ao apontar essa razão política grega como uma construção histórica radicalmente localizada, desfaz qualquer elo essencial entre a criação primeira do Direito e o pensamento ocidental que a reivindica como herança. Mas, esse radicalmente outro em que nos espelhamos por contraste na Grécia de Vernant pode, segundo uma de suas alunas, Nicole Loraux, nos servir como ponto de partida por meio de um anacronismo controlado ${ }^{4}$. Por esse anacronismo controlado, a fundação originária do Direito Ocidental se mostra como uma superfície tênue sobre o abismo da violência, cujo fluxo subterrâneo lhe é inerente e lhe dá apoio e mesmo legitimidade 5 .

Ao dar conotação pública ao fundo sensível, individual e privado, a lei adquire contornos contrários à vendeta, à vingança. Não é à toa que Sérgio Buarque de Holanda, ao iniciar sua célebre construção do traço estrutural de nossa civilização, a cordialidade, inicia recorrendo à imagem de Antígona. Inicia rememorando a relação dialética entre oikos e pólis, concreto sensível feminino e abstrato espiritual masculino, tal como aparece na leitura hegeliana da tragédia grega. Ao opor-se à lei da pólis, Antígona recorre à família, na família, a mãe libera no filho a força excedente, no irmão, o igual, no jovem, o esposo, que superam pela casa a abstração universal, em um traço carnal e diferenciador cordial. Sérgio Buarque recupera, como origem da abstração do cálculo das sociedades modernas, essa polarização grega entre família sensível e conceito universal. Onde Gilberto Freyre, em Casa grande E senzala, encontra uma mescla de virilidade e crueldade familiar, um afeto perverso produzido pela estrutura frouxa do latifúndio, Sérgio Buarque avança uma leitura sociológica de uma estrutura própria da não construção do espaço público, engolido no afetivo, pois não se produziu a negação dialética desse núcleo familiar, que se espraia, assim, nas 
ordens abstratas e universais, a contrapelo. Nesses termos, apesar de viver sob uma estrutura do Capital, moderna portanto, os sistemas brasileiros, jurídicos, políticos ou econômicos, nunca primaram pelo cálculo estrito da força ou do lucro, pelos meios que levam aos fins, ao contrário, o trabalho não precisava ser feito no mínimo de tempo, mas, como ordem familiar, no máximo de tempo possível, a fim de disciplinar, coibir o escravo ${ }^{6}$. Contra a própria administração abstrata do Capital, à qual, entretanto, deve-se até mesmo nosso surgimento histórico, convivem no Brasil estruturas anacrônicas, dissonantes, familiares, afetivas.

Nesse mesmo sentido, as políticas ditas públicas no país não parecem responder sequer a ordens do cálculo, como se pede de um liberalismo estrito, mas a uma ordem subjacente originária, informe, às ordens dispendiosas que parecem precipitar-se em direção ao caos dos laços de sangue, da mais pura vingança afetiva. Hannah Arendt, ao identificar, na insistência no caso judaico pelo nazismo durante a II Guerra, o mesmo irracionalismo ${ }^{7}$, explicita essa outra reminiscência que convive com uma sociedade administrada, abstrata de fundo moderno: seu outro não superado é a ordem violenta, que subjaz ao Direito, tanto em sua origem grega, quanto em sua face moderna de formalismo burocrático. O extermínio em massa era irracional não apenas do ponto de vista político ou social, mas mesmo estrutural, estratégico, levando à perda e desperdícios de forças que, na vigência de uma eficácia moderna, necessariamente deveriam estar voltadas à guerra. Esse dispêndio inútil de energia parecia romper a casca frágil do Direito, fazendo emergir um vingança demônica ${ }^{8}$. Talvez a mesma energia sem direção que Walter Benjamin antevê como fermento de uma greve geral, contra a qual o Direito e a Justiça instituídos precisavam a todo custo levantar-se, como detentores legítimos dessa violência que ameaçava irradiar-se sob outras figuras. Que a figura dessa força tenha sido canalizada para a mais irracional vingança de sangue, Benjamin também nos explica em suas Teses sobre o conceito de história. A energia sem vetor, liberada pelo descolamento das esferas legitimadas do poder, é esse fundo violento que, carreado para a ordem do Direito, uma vez liberto, reaparece ao se abrirem brechas no sistema. A energia sem sujeito que moveu populações em 2013 no Brasil, ou que atualmente move ocupações, pode vir dessa mesma ebulição. A exceção que

\section{Priscila R. Rufinoni}

Rito e violência - vigília pelos 111, por Nuno Ramos

6. Comentando Fernando Henrique Cardoso, Roberto Schwarz sintetiza: "Fundada na violência e na disciplina militar, a produção escravista dependia da autoridade, mais que da eficácia". SCHWARZ, Roberto. As ideias fora de lugar. In: Ao vencedor as batatas - forma literária e processo social nos inícios do romance brasileiro. São Paulo: Duas Cidades, 1977, p. 15.

7. Hannah Arendt, ao estudar a formação do totalitarismo e das "razões", ou possíveis "atos de estado", que teriam levado aos crimes na II Guerra, sublinha que "o que torna o argumento inaplicável aos crimes cometidos pelos governos totalitários e seus funcionários não é apenas que esses crimes não foram de modo algum induzidos pela necessidade, de uma ou de outra forma; ao contrário, poderíamos argumentar com força considerável que, por exemplo, o governo nazista teria sido capaz de sobreviver, até talvez de ganhar a guerra, se não tivesse cometido seus famosos crimes". ARENDT, Hannah. Responsabilidade pessoal sob a ditadura. In: Responsabilidade e julgamento. São Paulo: Companhia das Letras, 2004, p. 101.

8. Segui a sugestão de Willi Bolle em sua tradução do texto de Benjamin já citada em nota, que segue, por sua 
vez, a tradução francesa, na qual "demônio" é entendido no sentido do daimon grego, mantivemos a opção por traduzir dämonisch por "démonique" (demônico) e não "démoniaque". In: BENJAMIN, Walter. Crítica da violência - crítica do poder. In: Documentos de cultura

- documentos de barbárie (Seleção e apresentação de Willi Bolle). São Paulo: Cultrix, 1986.

9. BRASIL, Ministério da Justiça, Levantamento Nacional de Informações Penitenciárias - INFOPEN, dezembro de 2014, p. 33. camente instâncias de representação como a UNE e a UMES por essa energia liberada. Tal afronta pode vir, paradoxalmente, apenas a desnudar que as siglas representativas, na nova ordem que deslegitimou as instâncias de representação, já não representam a única força, ou o único vetor dessa força (ou da violência) que parece emergir sem figura fixa.

Quero pensar então a situação do Brasil, na qual talvez sequer a estrutura abstrata do Direito moderno tenha se formado de todo, pelo menos segundo a descrição clássica de Sérgio Buarque, ao aquilatar a cordialidade imanente às nossas formas de sociabilidade de superfície. Este artigo pretende rever algumas imagens recentes que tentam flagrar essa ordenação irracional, cujo princípio não é a Justiça, naquele seu sentido de um aprimoramento dos meios pelos fins, quer da sociedade, quer do Capital. Mas uma espécie de reposição da disciplina escravocrata em que o tempo deve ser consumido, colonizado, apropriado, não como elemento produtivo, ou como apropriação da força de trabalho abstrata, mas como elemento de poder hierarquizador, domesticador. Desse modo, talvez possamos entender as políticas públicas de segurança como disciplinadoras, muito distantes de um projeto, ou de qualquer forma de regulamentação racional moderna, de verniz social ou liberal que seja. Apesar de todas as mostras em contrário, do evidente dispêndio inútil de verbas e de energia social, o Brasil continua sendo um dos países que mais encarcera, que mais aplica penas disciplinares de cerceamento de liberdade para crimes não violentos. A se levar em conta os últimos dados do Levantamento Nacional de Informações Penitenciarias - INFOPEN, de 2014:

Se considerarmos os tipos penais propriamente ditos, temos que os crimes de roubo e tráfico de entorpecentes respondem, sozinhos, por mais de $50 \%$ das sentenças das pessoas condenadas atualmente na prisão. É importante apontar o grande número de pessoas presas por crimes não violentos, a começar pela expressiva participação de crimes de tráfico de drogas - categoria apontada como muito provavelmente a principal responsável pelo aumento exponencial das taxas de encarceramento no país e que compõe o maior número de pessoas presas. ${ }^{9}$ 
É um truísmo dizer que, segundo o mesmo levantamento, a maioria dessa população penitenciária é jovem, tem entre 18 e 24 anos, é negra ou parda. A porcentagem de negros e jovens encarcerados ultrapassa o percentual geral de negros e jovens na população brasileira. Também não é preciso lembrar mais uma vez que muitos, por volta de $40 \%$, estão presos sem processo formal ${ }^{10}$ e que a polícia brasileira é uma das que mais mata e mais morre no mundo ${ }^{11}$. Sem levar muito longe uma constatação que pode parecer ao mesmo tempo óbvia e escassamente fundamentada, a polícia brasileira é, por um lado, pouco profissional, o que faz dela vítima do próprio poder de que é agente. E, por outro, muito bem organizada como corporação, militarizada em larga porção, assim galvanizada, arraigada a processos de exceção rotinizados, tais como aqueles aperfeiçoados durante a ditadura - tortura, ausência de processo, provas pouco contundentes, pressuposição de culpa, sequestros etc ${ }^{12}$. Em ambos os casos, uma força policial pouco efetiva, se levarmos em conta um projeto público de segurança pautado pela eficácia, seja qual for o seu matiz político. Não parece haver perspectivas racionais para dar uma forma final coercitiva aos meios repressivos ${ }^{13}$. E a crueza com que se encara no Brasil o papel público da polícia, desnuda aquele interdito violento que Benjamin sublinha quanto ao lugar dessas corporações; guardiãs "de direito" do uso da força, "sua violência não tem figura, assim como não tem figura sua aparição espectral, jamais tangível, que permeia toda a vida dos Estados civilizado."14

Para Annateresa Fabris, no livro Arte e política, situações, um dos primeiros exemplos dessa tensão anacrônica captada em imagem é o B33 - Bólide caixa 18, homenagem a Cara de Cavalo, de Hélio Oiticica, de $1965^{15}$. Trata-se de uma caixa, um recipiente desmembrado para comportar, como urna funerária improvisada com os restos da sociedade, a efígie jornalística de Cara de Cava$\mathrm{lo}^{16}$. Comporta nos restos industriais, os restos mortais deste que foi consumido pela energia cumulada nas dobras violentas do cotidiano. Mesmo esses restos mortais são jornalísticos, repassados, mastigados, em suma, sociais. Ou, como escreve ao amigo morto Cara de Cavalo, o artista Hélio Oiticica:

Como se sabe, o caso de Cara de Cavalo tornou-se símbolo da opressão social sobre aquele que é marginal - marginal a tudo nessa sociedade: o

\section{Priscila R. Rufinoni}

Rito e violência - vigília pelos 111, por Nuno Ramos

10. Os dados são de 2014, divulgados pela Comissão Interamericana de Direito Humanos (CIDH) e pela Organização dos Estados Americanos (OEA).

Disponível em: $<$ http:// oglobo.globo.com/brasil/ quase-metade-dos-presosno-brasil-espera-julgamentorevela-relatorio-da-oea13840167\#ixzz4RgJS5FFX $\rightarrow$. Acesso em: nov. de 2016.

11. Segundo relatório de 2015 da Anistia Internacional, a polícia brasileira é a que mais mata no mundo. Em levantamento recente do jornal Guardian, verificou-se que a polícia brasileira mata em 6 dias o que a britânica matou em 25 anos. A mesma reportagem levanta 0 alto número de policiais brasileiros mortos, mesmo fora de expediente. Cf. BERCITO, Diogo. Polícia brasileira mata em 6 dias o mesmo que a britânica em 25 anos. Folha de S. Paulo, Cotidiano, 28 out. de 2016. Disponível em: <http://www1.folha.uol.com. br/cotidiano/2016/10/1827203policia-brasileira-mata-em-6dias-o-mesmo-que-a-britanicaem-25-anos.shtml $>$. Acesso em: nov. de 2016.

12. Ver SAFATLE, Vladimir; TELES, Edson (orgs.). 0 que resta da ditadura: a exceção brasileira. São Paulo: Boitempo, 2010.

13. Só como comentário, a partir dos poucos dados aqui levantados pelo The Guardian, houve uma evidente tentativa de desarmar e profissionalizar a polícia em vários países, houve uma evidente tentativa 
marginal. Mais ainda: a imprensa, a polícia, os políticos (...) - a sujeira

opressiva em síntese, elegeu Cara de Cavalo como bode expiatório, como inimigo público $\mathrm{n}^{\circ} 1(\ldots)$. Cara de Cavalo foi de certo modo vítima desse processo - não quero, aqui, isentá-lo de erros, não quero dizer que tudo

de desarmar e profissionalizar a polícia em vários países, dentro de políticas globais de desarmamento da população. No Brasil, ao contrário dessa tendência, fomos contra o referendo pelo desarmamento em 2005. Vale lembrar, ainda, que a Anistia internacional, em relatório supracitado, equipara a polícia brasileira à polícia norte-americana, principalmente em relação à abordagem das populações negras; tal como na ação da polícia brasileira, a violência parece enredada nos problemas não resolvidos da nossa herança escravocrata comum.

14. BENJAMIN, Walter. Para uma crítica da violência. In: Op. cit., 2011, p. 136.

15. FABRIS, Annateresa. 0 corpo como território do político. In: JAREMTCHUK,

Dária et al. (orgs.). Arte e política: situações. São Paulo: Alameda, 2010.

16. Remeto a um outro artigo sobre tema próximo, escrito no calor das manifestações de 2013 para um evento que tinha por foco pensar engajamento e política em tempos

contemporâneos. 0 artigo

foi publicado pela revista do Programa de Pós-Graduação em Artes Visuais da Universidade de Brasília. RUFINONI, Priscila. Mito e violência: 'Cara de Cavalo morto com 52 tiros em Cabo

Frio'. In: Revista VIS, vol. 13, n. 1, jan.-jun. de 2014.

17. OITICICA, Hélio. 0 herói e o anti-herói anônimo, Projeto Hélio Oiticica, Itaucultural, s/p. seja contingência - não, em absoluto! Pelo contrário, sei que de certo modo foi ele próprio o construtor de seu fim, o principal responsável pelos seus atos. O que quero mostrar, que originou a razão de ser de uma homenagem, é a maneira pela qual essa sociedade castrou toda possibilidade da sua sobrevivência, como se fora ela uma lepra, um mal incurável - imprensa, polícia, políticos, a mentalidade mórbida e canalha de uma sociedade baseada nos mais degradantes princípios, como é a nossa, colaboraram para torná-lo o símbolo daquele que deve morrer, e digo mais, morrer violentamente, com todo requinte canibalesco (...). Há como que um gozo social nisto, mesmo nos que se dizem chocados ou sentem "pena". Neste caso, a homenagem, longe do romantismo que a muitos faz parecer, seria um modo de objetivar o problema, mais do que lamentar um crime sociedade $\mathrm{X}$ marginal. ${ }^{17}$

Hélio Oiticica nota o requinte canibalesco dessa imolação pública, o gozo social, do qual, ele o sabe, também o artista ou a arte participam. O nosso coração selvagem, antropofágico, reivindicado como traço constitutivo em seu viés mais cruento e negativo. Pois a cordialidade sem polidez, Oiticica pressente, sem anteparo social, o informalismo mestiço, sensorial, pode cingir-se, ao fim, apenas ao laço maior de uma sociedade autoritária, cujo sadismo estabelece os lugares dos demais na ordem da família. Annateresa Fabris põe, nessa mesma linhagem, mas já distanciadas pelo filtro evidentemente político e não explicitamente lutuoso, a obra de Rosangela Rennó Atentado ao poder. Incluirei nesse rol, ainda, Imemorial. Ambas as obras citadas por Fabris, a de Oiticica e de Rennó, se valem do último resquício aurático da presença, aquele olhar pregnante da imagem fotográfica, ambas falam de um inominado, de um anonimato constitutivo desse gozo social. Imemorial, de Rosângela Rennó, retoma as fotos de candangos que, de um passado extinto e iletrado, nos fitam como a força muda sob os alicerces de Brasília. Para nosso argumento, interessa mais Atentado ao poder. Rennó se utiliza de fotos de homens assassinados publicadas em jornais como A notícia e O povo na rua durante a conferência 
Rio 92, sobre o meio ambiente. Em concomitância à arena pública mundial ilustrada, as fotos, dispostas rente ao chão e na vertical, configuram uma espécie de "balé macabro", nas palavras de Fabris. Os membros inertes, pela verticalidade em que se dispõem as fotos, parecem erguer-se, exibindo a força que lhes foi arrancada, em uma afronta post mortem. Uma luz neon, artificial, fria, emana dos retratos apoiados no chão, como uma espécie de luminosidade citadina, com seus letreiros e luzes indiferentes. Os homens - mortos - se põem sob a tutela da ideia abstrata, tão postiça e moderna quanto o neon, ideia importada e fora de lugar: "The Earth summit".

A linhagem de Cara de Cavalo e desses mortos que dançam sob a luz mortiça de uma cidade contemporânea qualquer, sob uma cúpula legisladora tão distante quanto incompreensível, tem na fotografia, na fotografia reapropriada do jornal, seu parentesco formal. Mais do que mera técnica, é a imagem arrancada do discurso comum, do cotidiano, que, deslocada da grade paratática do jornal, mostra-se como constante, como traço estrutural, como lastro familiar. No mesmo ano da conferência sobre o meio ambiente, resposta ao massacre ocorrido em 2 de outubro de 1992 no gigantesco complexo penitenciário do Carandiru em São Paulo, Nuno Ramos criou 111.

À diferença das outras propostas citadas, Ramos não se valeu de imagens fotográficas, muito embora elas tenham proliferado à exaustão, como grandes cenas de Pogroms, em todos os jornais. Nuno Ramos, entretanto, escolhe dar a seu trabalho um tom monumental, entre arcaico e rústico, a partir de matérias brutas como breu, vaselina, ouro, fumaça ${ }^{18}$. O título é apenas o número, signo vazio da contagem dos mortos. Podemos pensar que, como sugere Theodor Adorno, esse formalismo distanciado, mítico, concede ao monumento um caráter pétreo, egípcio. Aquele formalismo egípcio da arte autônoma, remetida a si mesma em sua estrutura, para que desse interior pudesse explicitar sua historicidade tensa. Não à toa, às estruturas rudes e horizontais que demarcam uma espécie de via, Nuno Ramos dá o nome de múmias, múmia de barro, de cinza, de ouro. No meio do caminho, outro arco metálico vertical cruzado na horizontal (cruz) carrega os nomes gravados em linotipia. Uma pequena individualização mínima, diante dos fragmentos e dos paralelepípedos que se põem, cada um no seu espaço, como matéria

\section{Priscila R. Rufinoni}

Rito e violência - vigília pelos 111, por Nuno Ramos

18. Para uma descrição da obra, nos valemos do site oficial de Nuno Ramos. Disponível em: $<$ http://www.nunoramos. com.br/portu/comercio. asp?flg_Lingua $=1 \& \operatorname{cod}$ Artista $=94 \&$ cod_Serie=23 $>$. Acesso em: nov. de 2016. 

como a palavra, calcinados, aniquilam-se. Nesse sentido, parece quase uma excrescência tola, um pequeno senão narcísico, a aderência de trechos do livro de poemas Cujo, que o autor publicará no ano seguinte à instalação em 1993, às paredes e às tampas das caixas que contém as cinzas dos salmos. Uma excrescência que é uma espécie de alento, uma escapadela, na brutalidade muda das pedras. Mas essa brutalidade é que faz espelhar o cosmos inferior, esse de pedra, ao cosmos superior, em uma espécie de carta astral: na segunda sala, estão dispostas fotos de satélite de São Paulo no dia do acontecimento. A fumaça em grandes receptáculos de vidro enovela essa relação de cópula entre a revolução dos astros e a revolução humana, como um mapa astral que assinala os homens. Se o Direito é apenas uma ordem humana, que condena ao crime e não ao castigo, delimitando as áreas de atuação da violência, o espaço inumano remete novamente ao todo que aniquila, para o qual não há nomes, numes ou norma. O espaço anterior ao mito e ao Direito, que dá forma a ambos. Esse todo que se entrevê, egípcio e monumental, pode nos explicitar algo de uma violência anterior, afetiva, que move o gozo social da vingança primitiva, anterior a qualquer cálculo do nomóteta, a qualquer ordem estabelecida por Direito. Na múmia de ouro, na qual uma pequena ascese é evocada, um rito cruel que demarca a impossibilidade dos ritos abstratos de luto. Há uma frase mítica para esse luto público interrompido, repetida hoje nos meios digitais, antes por outros modos. Mítica pois é a manifestação renitente da violência, distante da sua aplicação na ordem dos fins e dos meios. É a ladainha coletiva brasileira, quando se evoca essa última linha áurea, ínfima, para a nomeação do que é humano:

19. TJ anula julgamentos que condenaram 74 PMs no massacre do Carandiru. Folha de S. Paulo, Cotidiano, 27 set. de 2016. Disponível em: <http:// www1.folha.uol.com.br/ cotidiano/2016/09/1817306-tjanula-julgamentos-que-condenaram-pms-no-massacredo-carandiru.shtml $>$. Acesso em: nov. de 2016. "bandido bom é bandido morto, se está com pena, leva para casa", como se todo o desenho da humanidade se resumisse, sempre e mais uma vez, à ordem do oikos, ao círculo mítico do sempre o mesmo, à domesticação patriarcal, aos laços cruéis de um afeto invasivo, repelente, deformador.

Em 2016, como sabemos, as penas aos responsabilizados pelo crime de 1992 foram suspensas ${ }^{19}$. Quando a condenação pela ordem humana do acontecimento foi cancelada, a partir das pe- 
quenas relações jurídicas, engrenagens técnicas, calculadas para sobrepesar crimes e culpas, o artista não clama por "justiça”. Essa Justiça que já de antemão move-se pelo seu avesso, pelo clientelismo, pela lei do sangue e da proximidade, pelo mito. Uma justiça fora de lugar, na qual a tecnicidade dos meios que justificam os fins na ordem do Direito não é nem mesmo ideológica, já que se sabe mera manifestação cínica, pois formalista, de poder puro. E a falta de assombro ante as prisões sem processo, ou de uma chacina, só explicita tal ordenamento de um Direito que se manifesta fora da sua própria regra. Nuno Ramos diz que não quer discutir as tecnicidades do jurídico, não era essa sua proposta, já que condenar ou não os pequenos agentes nada significa para as vítimas, mas sim nomear cada um uma última vez, para o céu, ou para além dessa ordenação humana que, no Brasil, nunca se concluiu de todo como norma. A ideia original remonta a uma instalação sonora, ao que se depreende projetada para a Bienal de 2012, conforme está descrita no site oficial do artista:

"O DIA DELES - 24 HORAS 111 ” será a leitura contínua, por 24 horas ininterruptas, dos nomes dos presos assassinados em 2 de outubro de 1992 pela polícia militar do Estado de São Paulo, em episódio conhecido como o massacre do Carandiru. Esta leitura será levada ao ar, sem qualquer interrupção, pela Mobile-Radio, entre 0:01 horas e 23:59 minutos dos dia 2 de outubro de 2012. 24 leitores emprestarão suas vozes para este réquiem sonoro, perpetrando a leitura durante uma hora cada um. ${ }^{20}$

A proposta de 2012 repete-se em 2016, agora com auxílio da internet. Trata-se como em todo ciclo ritual, de repetição, da forma do rito ou dos nomes dos mortos; repetição das pequenas cifras individualizadoras que nos antepõem ao nada. Aliás, como propõe o antimonumento Imemorial de Rosangela Rennó, a partir das faces sem nome. Ou nas palavras do próprio artista para a Folha de S. Paulo:

Pensei num lugar alto, como se fosse uma antena a irradiar esses nomes pela cidade (...) São as palavras tentando se materializar de todas as formas. Arte é presença, e um nome é um mínimo de presença. ${ }^{21}$
Priscila R. Rufinoni

Rito e violência - vigília pelos 111, por Nuno Ramos

20. Fonte: site oficial de Nuno Ramos, cit.

21. MARTí, Silas. Com público de 1 milhão, acaba ato de Nuno Ramos por mortos do Carandiru. Folha de S. Paulo, Ilustrada, 02 de novembro de 2016. Disponível em: <http:// www1.folha.uol.com.br/ ilustrada/2016/11/1828761com-publico-de-1-milhaoacaba-ato-de-nuno-ramospor-mortos-do-carandiru. shtml>. Acesso em: nov. de 2016. 

tratava-se mais de um rito pré-estabelecido, uma vigília, como diz a página do artista na internet, que devem ser cumpridos - ler os nomes 24 vezes, em 24 horas, em um lugar "escolhido", e nesse sentido ínfimo, con-sagrado - que algo para ser visto, ouvido, compreendido ou exposto. O próprio artista diz que "não queria plateia”. Não há uma re-apresentação do real sob outra moldura, não há forma alegórica que conceda à arte um lugar - privilegiado no mais das vezes - de discurso sobre o que aborda, não há elaboração poética sequer. Mesmo o "lugar sagrado" resumia-se a um apartamento comum em um andar elevado, do qual se descortinava ao longe a cidade. A fala não rememora a fama, não canta as sereias dos feitos, as aventuras. Não há nenhuma tentativa de criar heróis, como ainda havia talvez em Oiticica, nem de conceder um heroísmo moderno ao que chamamos de arte. Nenhum heroísmo, antes uma confissão de apequenamento diante do que aniquila.

A sala com as fotos de satélites em 1992 poderia, talvez, apontar para uma justiça última, e para um possível papel de comentário externo à sociedade próprio à arte. Um último heroísmo. Os trechos do livro Cujo, em sua tendência de já pensar a palavra como um índice de matéria, impedem qualquer ideia nesse sentido, pois tal literatura é uma literatura de indistinção, sem referencialidade explícita. Apesar de um tanto deslocados do todo, como comentamos, esses trechos do livro já prenunciam uma relação não referencial com o discurso. Próxima demais à pura matéria antes da forma. Lembro aqui outra proposta do artista

22. Para descrição da obra em questão, ver site oficial de Nuno Ramos, já citado. em torno da palavra, Mácula (1994) ${ }^{22}$, instalação na qual grandes pontos de uma escrita em braile gigantesca tomam a parede. $\mathrm{O}$ visível dos pontos, sua presença reiterada pela dimensão, tornam a escrita ilegível ao toque. O que é visível, em sua manifestação pura, o é por ser ilegível. Quase uma nomeação mítica, cuja função não é comentar sobre, dizer isto sobre isto, não é discursiva, mas presencial, apenas um pôr "algo". Também em 111, as palavras se dissolvem no branco da parede, ou em uma espécie de véu que fecha as salas, no qual o texto é translúcido, no limite da legibilidade. O próprio título, o número de corpos, é pouco narrativo, discursivo, 
mas não deixa de lembrar que é um número emblemático, pois foi escondido pelo governo do Estado de São Paulo até o fechamento da eleição municipal de 1992, no domingo, 03 de outubro, dia seguinte ao massacre ${ }^{23}$. Nessa perspectiva material (e de Realpolitik, se se pode dizer), os astros não se descentram estultos diante da estultícia do homem, também não há, nessas cartas astrológicas, qualquer signo da boa estrela a marcar um destino, não há fortuna ou infortúnio assinalado, como era comum às biografias antigas, há apenas astros indiferentes que miram a terra, como a fumaça que se concentra nos vidros, laçada aos céus urbanos tal qual o neon de Rosangela Rennó. Assim, a frágil múmia, estropiada, é o único luto possível, mínimo, mudo. Aliás, todas as partes dessa instalação tendem ao desarranjo, ao mínimo, são menos que coisas, espécies de verticais mal erigidas sobre trastes horizontais, cavaletes pensos, dejetos. Seria, talvez, importante lembrar que Nuno Ramos se inscreve em debates maiores sobre as artes, que suas instalações não são apenas produto da leitura do país, não estão (e também não estamos) circunscritas em um embate com a formação de uma arte brasileira. E que mesmo a perspectiva de uma violência mítica como fundo do Direito aponta para uma característica menos histórica, menos brasileira, e mais universal. A própria recorrência a autores como Arendt e Benjamin localizam o nosso debate em um lugar perigoso de abstração. Mas talvez possamos pensar, dentro de nosso argumento, que essa justiça formal humana, aquela cuja norma é social, política, e que se inicia no corpo da filosofia grega, cada vez mais abstrata e não sanguínea, para nós é ainda informe, postiça, falsa. Nossa devoração sensorial, anterior ainda ao conceito, essa sensibilidade pura muitas vezes assumida pela vanguarda artística brasileira como traço formativo próprio, pode ser o diferencial também que nos põe como contraexemplo desvelador. No fim das contas, dizemos a todo momento com uma piscadela, a ideologia de uma abstração universal não é nem mesmo uma máscara de autoengano, é mascaramento sobre mascaramento. Só uma ingenuidade sensível mítica, ou um cinismo cúmplice ou, ainda, a simbiose íntima dos dois -, pode nos fazer crer em frases ditas tantas vezes na nossa mídia cotidiana, de que "eu só agi em relação à Lei”, que se faz cumprir "a Lei”, que a polícia nos protege pela "Lei”. Perto do coração selvagem, ainda sem caráter,

\section{Priscila R. Rufinoni}

Rito e violência - vigília pelos

111, por Nuno Ramos

23. Na entrevista com o perito Osvaldo Negrini Neto, em 2012, há detalhes desse momento posterior à chacina em que se tentou mascarar o ocorrido de várias formas. 0 perito diz, na entrevista: "No domingo [logo após o massacre], seria dia de eleição [municipal] e havia uma necessidade enorme de não se divulgar nada, pelo menos até lá. E, de fato, só foi divulgado que o número de mortos era maior que 90 no final da tarde, quando se fecharam as eleições". "Nunca vi algo tão desumano' conta perito ao lembrar o massacre.Agência Brasil, 01 out. de 2012. Disponível em: <http://ultimosegundo.ig.com.br/brasil/ sp/2012-10-01/nunca-vi-algotao-desumano-conta-peritoao-lembrar-massacre.htm>. Acesso em: nov. de 2016. 

condena segundo um crime, mas a mais primitiva vingança, crua, sem abstrações.

Vale lembrar que o massacre se deu sob o governo de Luiz Antônio Fleury Filho, do PMDB, e o seu secretário de segurança, Pedro Franco de Campos, foi substituído por Michel Temer seis dias após a chacina, no dia 8 de outubro. O Coronel Ubiratan Guimarães, responsável pela operação irracional, mal conduzida e desastrosa, foi eleito deputado depois do ocorrido, condenado e absolvido em um segundo julgamento, sendo executado a tiros em 2006, na mesma ordem da vendeta instituída. Para não deixar de dar nomes aos envolvidos. 